\title{
Producción de tomate tipo italiano en función del volumen de la celda y de la edad de las mudas
}

\author{
Victoria Rossmary Santacruz Oviedo ("); Keigo Minami \\ Escola Superior de Agricultura “Luiz de Queiroz” (ESALQ/USP), Departamento de Produção Vegetal, Caixa Postal 9, 13418-900, \\ Piracicaba (SP), Brasil. \\ (*) Autora correspondente: vrossmary@hotmail.com
}

Recibido:16/ago./2011; Aceptado: 9/dez./2011

\begin{abstract}
Resumen
Con el objetivo de evaluar la influencia de las bandejas de celdas sobre la producción de tomate tipo italiano en el campo, se realizó este trabajo en Piracicaba, SP, Brasil, de mayo a agosto del 2005. Los tratamientos consistieron en cuatro volúmenes de recipiente, tres bandejas de poliestireno expandido de 121,$2 ; 34,6$ y $12,0 \mathrm{~cm}^{3}$ y de una bandeja de plástico rígido de $14,0 \mathrm{~cm} 3(72$, 128, 288 y 450 celdas, respectivamente) combinadas con cuatro edades para el trasplante (19, 24, 29 y 34 días después de la siembra). El delineamiento para la producción de mudas fue completamente al azar, con cinco plantas por parcela y tres repeticiones. Se analizaron área foliar, altura, masa verde y seca de la parte aérea y raíz y la calidad de las mudas. En la producción a campo, el delineamiento fue en bloques al azar con diez plantas por parcela y tres repeticiones. Fueron evaluadas la precocidad para inicio de cosecha, producción comercial y total por planta. Volúmenes mayores de recipiente (121,2 y 34,6 cm³) presentaron mejor calidad de mudas. En la producción de frutos, el número comercial y total de frutos por planta fue superior en la muda de 24 días de edad, sin embargo, en la producción total de frutos, no hubo diferencia entre los tratamientos. Por otro lado, también se obtuvo precocidad para la cosecha en los tratamientos realizados en los volúmenes de 121,2 y $34,6 \mathrm{~cm}^{3}$. El volumen de recipiente de $14,0 \mathrm{~cm}^{3}$ (450 celdas) resultó en mudas de calidad muy inferior, alongadas y raquíticas.
\end{abstract}

Palabras clave: Lycopersicon esculentum Mill, cv. Neptuno, número de frutos, calidad.

\section{Produção de tomate tipo italiano em função do volume do recipiente e da idade das mudas}

\section{Resumo}

Com o objetivo de avaliar a influência de bandejas de células na produção de tomate tipo italiano no campo, este trabalho foi realizado em Piracicaba (SP), Brasil, de maio a agosto de 2005. Os tratamentos consistiram de quatro volumes de recipiente, três bandejas de poliestireno expandido de 121,2; 34,6 e 12,0 cm³ e uma bandeja de plástico rígido de 14,0 cm³ (72, 128, 288 e 450 células, respectivamente), combinadas com quatro idades de transplante, 19, 24, 29 e 34 dias depois da semeadura. 0 delineamento para a produção das mudas foi inteiramente ao acaso, com cinco plantas por parcela e três repetições. Foram analisadas a área foliar, a altura da muda, a massa fresca e seca da parte aérea e da raiz, assim como a qualidade das mudas. No campo, o delineamento foi em blocos ao acaso com dez plantas por parcela e três repetições. Avaliaram-se a precocidade para início da colheita, a produção comercial e a produção total por planta. Nos recipientes de maiores volumes, foi observada a melhor qualidade de mudas (121,2 e 34,6 cm³). Quanto à produção de frutos, o número comercial e total de frutos por planta foi superior no transplante aos 24 dias, porém para a produção total de frutos, não houve diferença entre os tratamentos. Observou-se precocidade para a colheita nos tratamentos realizados nos volumes 121,2 e 34,6 cm³. O volume 14,0 cm³ (450 células) resultou em mudas de baixa qualidade, estioladas e raquíticas.

Palavras-chave: Lycopersicon esculentum Mill, cv. Netuno, número de frutos, qualidade.

\section{Effect of tray cell size and seedling age on italian type tomatoes production}

\begin{abstract}
The aim of this study was to evaluate the influence of cell trays on the production of Italian type tomatoes (Lycopersicon esculentum Mill) in the field. This study was carried out in Piracicaba (SP), Brazil, from May to August 2005. The treatments consisted of four recipients with three expanded polystyrene trays, measuring 121.2; 34.6, and $12.0 \mathrm{~cm}^{3}$ and one tray of rigid plastic, measuring $14.0 \mathrm{~cm}^{3}$ (72, 128, 288 and 450 cells, respectively) combined with four vegetative ages at transplanting (19, 24, 29 and 34 days after sowing). A randomized experimental design was done for the production of seedlings, by using five plants per plot and three replications. The leaf area, the height, the fresh and dry mass of the aerial part and the root, and the quality of the seedlings were analyzed. In the field production, the statistical design was a randomized block, using ten plants in each row with three replications. Harvest precocity was evaluated, as well as the commercial and total production of each plant. The larger volume trays (121.2 and $34.6 \mathrm{~cm}^{3}$ ) caused the best quality of seedlings. On fruit production, the commercial and the total number of fruits per plant were superior in the seedlings of 24 days of age. However, there was no difference between the treatments for the total fruit production. The treatments performed in the recipients of 121.2 and $34.6 \mathrm{~cm}^{3}$ presented a gain in the harvest precocity. The tray cells of $14.0 \mathrm{~cm}^{3}$ (450 cells) provided poor quality, elongated and stunted seedlings.
\end{abstract}

Key words: Lycopersicon esculentum Mill, cv. Neptune, fruit number, quality. 


\section{INTRODUCCIÓN}

Existen varios factores conocidos que afectan la producción de tomate desde la producción de mudas hasta la cosecha. Entre ellos, uno de los factores más significativos es la calidad de las mudas obtenidas. Alta calidad del trasplante es esencialmente importante para el éxito de la producción de tomate, porque la condición de la planta afectará el cuajado de los frutos, la la precocidad de la producción, la producción total y el tamaño de los frutos. Minami (2010) mencionó que el tamaño de la muda y del recipiente, el sustrato, la nutrición antes y después del trasplante, y la edad de las mudas son factores muy importantes para el éxito de la producción.

Desde el punto de vista económico, la producción en larga escala de mudas de alta calidad ha motivado a los productores a adoptar nuevas técnicas, métodos y equipamientos. La disponibilidad de bandejas de diferentes materiales y tamaño de celdas, de sustratos artificiales o naturales listos para su utilización y la posibilidad de automatización de muchas operaciones como siembra, irrigación, fertilización, control fitosanitario y manejo de ambiente, han reducido los costos y aumentado la calidad de mudas producidas (Pereira y Martinez, 1999). Según Vabrina (2002), el tamaño del recipiente tiene gran importancia económica en la producción de mudas, siendo muy variable en el comercio. Así, el viverista prefiere las bandejas con menor número de celdas, lo que significa mayor número de mudas producidas por $\mathrm{m}^{2} \mathrm{de}$ invernadero, representando menor cantidad de sustrato y menor costo de producción. Sin embargo, los productores prefieren mudas producidas en bandejas con mayor número de celdas y mayor volumen de recipiente, lo que representa mejor calidad de mudas. Godoy y Cardoso (2005) resaltan que la economía lograda con la utilización de volumen menor puede perjudicar la producción final, porque puede ser insuficiente para el desarrollo adecuado de las mudas impidiendo que los cultivares disponibles expresen su potencial. Para la producción en bandejas, cada especie presenta una adaptación a determinado número de celdas dependiendo del volumen del recipiente. La edad de la muda para el trasplante es considerada un factor fundamental, debido a que el tiempo de permanencia de ésta en un volumen reducido de substrato puede comprometer su desempeño en el campo. Vabrina y Orzoleck (1993) mencionan que las investigaciones sobre la edad de la muda de tomate son realizadas desde hace 70 años y que todavía existe falta de métodos estandarizados de producción de mudas. Según Seabra et al. (2004), la influencia de varios de los factores mencionados, no está siendo detectada por los investigadores, visto que varios de los trabajos relacionados con mudas no son conducidos hasta el final del ciclo, interrumpiéndose en la fase de trasplante, o se realizan como máximo, hasta el cuajado de los frutos.
La utilización de bandejas de plástico laminado de 450 celdas en algunas regiones productoras de tomate, especialmente en el Estado de Goiás (Brasil), se ha adoptado para la producción de mudas y es probable que entre otros factores, su utilización influya en la producción, porque las mudas son producidas en volumen muy reducido de recipiente y son trasplantadas muy precozmente lo que podría afectar la producción en el campo. En la literatura todavía no existen datos de trabajos desarrollados con las bandejas de 450 celdas $\left(14,0 \mathrm{~cm}^{3}\right.$ de volumen) en la cultura del tomate. En este trabajo fue abordado el estudio de la bandeja de 450 celdas, comparando con otros tipos comerciales que ya fueron evaluados, para determinar la influencia del volumen de recipiente y la edad de trasplante en la producción de mudas y en la producción a campo de tomate tipo italiano.

\section{MATERIAL Y MÉTODOS}

El experimento fue realizado en Piracicaba, SP, Brasil, a $22^{\circ} 43^{\prime}$ latitud sur, $47^{\circ} 38^{\prime}$ de longitud oeste y altitud de $540 \mathrm{~m}$. Según la clasificación de Köpen, el clima de la región es CWa: tropical húmedo, con tres meses secos, lluvias de verano y sequía en el inverno. El suelo es clasificado como Nitossol Rojo Eutrófico, de textura arcillosa. Los tratamientos para la producción de mudas resultaron en una combinación factorial de $4 \times 4$, siendo el primer factor los cuatro volúmenes de recipiente de 121,2; 34,6; 12,0 y $14,0 \mathrm{~cm}^{3}$ correspondientes a las bandejas de poliestireno expandido de 72, 128, 288 celdas y de plástico rígido, de 450 celdas y las cuatro edades de trasplante de 19, 24, 29 y 34 días después de la siembra (DDS). Se utilizó el cultivar híbrido Neptuno (BHN Seed), tipo italiano, de hábito de crecimiento indeterminado. Las mudas fueron producidas en casa de vegetación, provista con equipo de riego (microapersores), se utilizó substrato comercial, sin fertilización adicional. La producción de mudas en las bandejas fue dispuesta en un delineamiento totalmente al azar, con cinco plantas por parcela y tres repeticiones. La siembra fue realizada el día 06/05/2005. En el día del trasplante fueron evaluadas las siguientes características: área foliar (AF), altura de las mudas (A), masa verde y seca de la parte aérea (MVa y MSa), masa verde y seca de raíz (MVr y MSr) y la calidad de las mudas. Para la obtención de la altura de la muda, se utilizó un paquímetro manual y se consideró desde el nivel del sustrato hasta el meristema apical. En la obtención de la masa verde de la parte aérea, se utilizó toda la parte aérea encima del nivel del substrato. Para la obtención de la masa seca fue utilizada la misma muestra de cinco plantas por parcela y tres repeticiones. Posteriormente fueron acondicionadas en sacos de papel y llevadas a la estufa a una temperatura de $65^{\circ} \mathrm{C}$ por 48 horas. La obtención de la masa verde y seca de la raíz se extrajo de la muestra anterior y se realizó 
el mismo procedimiento anterior. Como calidad fue considerado el aspecto general de la muda, hojas verdes y vigorosas, ausencia de enfermedades, acúmulo de raíces al momento de trasplante. Para la producción en el campo el delineamiento experimental fue bloques al azar, con diez plantas por parcela y tres repeticiones. Fueron evaluadas seis plantas centrales. La combinación factorial resultante fueron los cuatro volúmenes de recipiente utilizados y las cuatro edades de trasplante. Fueron evaluados la precocidad para la cosecha por medio del número de frutos y masa precoz (P) por planta, número total (NTf) y comercial de frutos (NCf) por planta, masa total (MTf) y comercial (MCf) de frutos por planta. Para la obtención de la producción precoz fueron evaluados los frutos de las dos primeras cosechas. La distancia utilizada entre plantas fue de $0,60 \times 0,80 \times 1,20 \mathrm{~m}$, hileras dobles, y la conducción fue realizada con dos tallos por planta. Las fertilizaciones fueron hechas de acuerdo a las recomendaciones para el cultivo (Alvarenga, 2004), el riego fue por goteo y se utilizó cobertura de suelo (plástico negro). La cosecha se inició cuando los frutos presentaron entre $40-50 \%$ de coloración roja, en un total de seis cosechas. Los frutos fueron clasificados en pequeños, medianos y grandes de acuerdo a la legislación vigente (BRAsil, 1995). Después de la clasificación de los frutos se obtuvo la masa de los mismos. Todas las características fueron analizadas considerándose la media por planta. Para el análisis de los datos se utilizó el programa estadístico MS-Estat, realizándose la comparación de las medias por el test de Tukey $(\mathrm{p} \leq 0,05)$ y para la edad de las mudas, fue realizada análisis de regresión.

\section{RESULTADOS Y DISCUSIÓN}

\section{Producción de mudas}

Para las características evaluadas en el momento del trasplante, se encontraron interacción significativa entre los factores estudiados, volumen de celda y edad de trasplante de la muda (Figura 1). Las mudas de tomate producidas en mayor volumen de recipiente presentaron mayor área foliar en relación a las mudas producidas en menor volumen de recipiente, sin embargo, fue proporcional la edad de la muda para todos los tratamientos (Figura 1a). Esta diferencia de área foliar puede ser debido a que cuanto más espacio tienen las raicillas de las mudas en las celdas, el crecimiento del sistema radicular es más abundante y por lo tanto, la parte aérea encuentra más soporte y se desarrolla mejor. Además, se debe considerar que la densidad poblacional de las mudas afecta el desarrollo aéreo y la arquitectura de la muda. UlLé (2009) menciona que cuando mudas de hortalizas son sembradas en bandejas, su tasa de crecimiento es proporcional al volumen individual de cada celda, coincidiendo con el resultado en este estudio. SEABra et al. (2004) trabajando con mudas de pepino, encontraron que las mudas producidas en mayor volumen de celda presentan poca restricción radicular, optimizando la provisión de nutrientes, agua y luz y favoreciendo la mayor expansión de hojas. También fueron encontradas tendencias de mayor área foliar en recipientes con mayor volumen en los cultivos de sandía (Liv; i 995; LaTimer, 1991; Seabra et al., 2004), lechuga (Trani et al., 2004), berenjena (UlLE, 2009). Los recipientes de mayor volumen poseen mejor capacidad para retener a la planta por un periodo de tiempo más largo, lo que beneficia los casos en que el trasplante será realizado tardíamente.

La altura (A) de muda es otro indicador del buen desarrollo radicular. Los tratamientos presentaron tendencia de crecimiento lineal, de acuerdo a la edad de trasplante, con excepción de la bandeja de 72 celdas, pero no siempre ese aumento fue proporcional al volumen de la celda, como el caso de la bandeja de 450 celdas (de menor volumen), donde las mudas presentaron mayor altura por efecto del alargamiento de las plántulas. La bandeja de 72 celdas presentó tendencia de crecimiento cuadrático, duplicando el crecimiento en altura de las mudas en la última semana de este experimento. La tendencia de aumento de la altura con la edad también fue observado en melón por Rizzo et al., (2000) y en tomate (WeSTON y ZANDSTRA, 1986), quienes propusieron que el aumento en la altura (A) está directamente relacionado a la densidad poblacional, debido a la competencia por luz. La densidad poblacional en la bandeja de 450 celdas afectó especialmente la calidad de las mudas (color verde con escasa pigmentación, alargadas, con talluelos deformados, encurvados) agravándose en la tercera semana de evaluación, donde hubo mayor competencia por luz, lo que resultó en mudas alargadas de baja calidad. Las bandejas de 72 y 128 celdas, no presentaron problemas por la densidad poblacional hasta los 34 días, tiempo máximo de este experimento en el vivero (Figura 1b). Con relación a la masa verde aérea, la respuesta fue lineal en función a la edad de la muda para todos los tratamientos, es decir, independiente al volumen de recipiente, cuánto más edad tenga la muda, se genera mayor masa verde aérea $(\mathrm{MVa})$, lo cual, no representa necesariamente buena calidad de muda (Figura 1c). La diferencia entre los volúmenes de 14,0 y $12,0 \mathrm{~cm}^{3}$ en términos de volumen de celda es muy pequeña, apenas de $2,0 \mathrm{~cm}^{3}$, pero en términos de número de celdas (una diferencia de 272 celdas más) indica mayor densidad poblacional. Esa diferencia presentó influencia en la masa verde aérea (MVa) y altura (A), debido a que en la bandeja con más número de celdas, existe mayor competencia por luz y como resultado se tuvo mayor crecimiento de las plántulas, pero con la obtención de mudas sin uniformidad y alargadas. En este caso debe tenerse mucho cuidado con la edad del trasplante, ya que desde la tercera semana de evaluación, la calidad de las mudas puede disminuir en términos de color, uniformidad, vigor, acúmulo de raíces, en las celdas de menor volumen. 
Para la masa seca de la parte aérea $(\mathrm{MSa})$ y masa seca de la raíz (MSr) las mudas desarrolladas en volúmenes mayores también presentaron mayores acúmulos (Figuras 1d, 1f). Resultados semejantes también fueron encontrados en pepino (SEabra et al., 2004). La masa seca aérea (MSa), aumentó linealmente en función del tiempo de evaluación en las bandejas de 72, 128 y 450 celdas. Sin embargo, el análisis de regresión para la masa seca aérea (MSa) y la masa seca de la raíz $(\mathrm{MSr})$ de la bandeja de 288 células $\left(14 \mathrm{~cm}^{3}\right)$ presentó tendencia de ajuste cuadrático, notándose paralización de acúmulo de MSa y disminución del acúmulo desde los 29 días de edad, siendo el crecimiento de la parte aérea afectado por la restricción radicular. En este punto es importante destacar que el volumen de $14 \mathrm{~cm}^{3}$, no es adecuado para mantener por periodos mayores a 29 días en el vivero, por los síntomas de estrés (amarillamiento de hojas, paralización del crecimiento) que presentaron las mudas para las condiciones de este experimento, donde no se realizó nutrición adicional (Figura 1d). Puede decirse que ese volumen permite el crecimiento de la raíz hasta cierto punto, a partir del cual el crecimiento de la raíz disminuye. De acuerdo a RuFf et al., (1987) la restricción en el volumen del sustrato reduce el crecimiento y altera la morfología de la raíz de plantas de tomate. Entre los volúmenes menores estudiados, las plántulas desarrolladas en la bandeja de 288 celdas, presentaron algunas alteraciones en su desarrollo, asociado al volumen reducido de

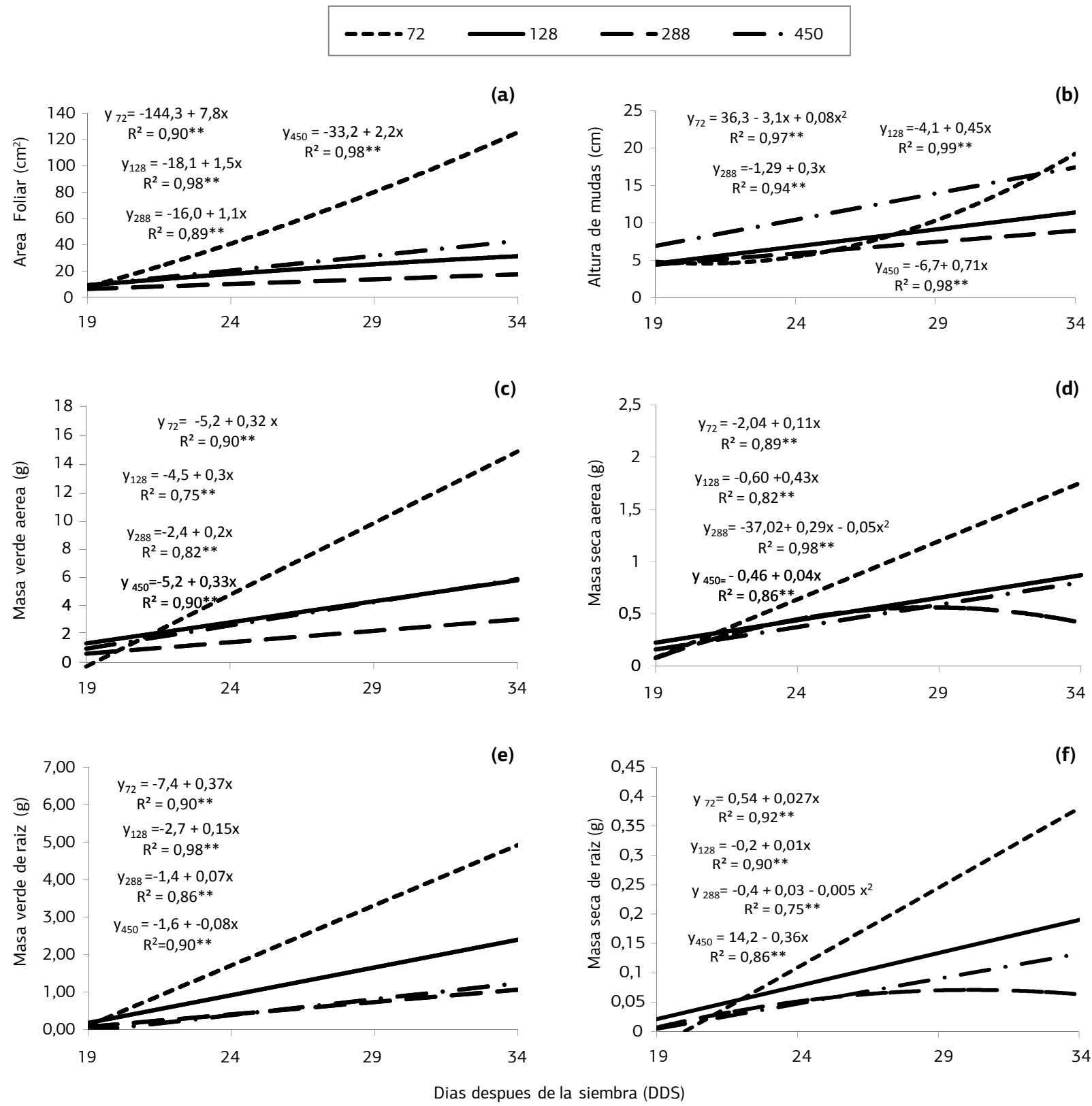

Figura 1. Área foliar (a), altura de mudas (b), masa verde y seca aérea (c, d), masa verde y seca de raíz (e, f) de mudas de tomate 'Neptuno' en función de la edad (días después de la siembra) y el volumen del recipiente $\left(\mathrm{cm}^{3}\right)$. 
celdas, probablemente también fue afectado por la profundidad de la bandeja ( $44 \mathrm{~mm})$, que no permitió un desarrollo óptimo de la muda comparando con los otros volúmenes utilizados. Además, se observó en las últimas semanas de evaluación, amarillamiento de las hojas en dicho tratamiento. Es posible, que el sustrato haya necesitado mayor frecuencia de irrigación en edades más avanzadas, además de nutrición adicional. Si bien la bandeja de 450 celdas presenta un volumen menor $\left(12 \mathrm{~cm}^{3}\right)$ la profundidad de la celda es mayor $(48 \mathrm{~mm})$ a la bandeja de 288 celdas, lo que pudo favorecer el mejor crecimiento radicular. En este trabajo no se evaluó la influencia de la profundidad de la celda, pero por presentar resultados diferentes la bandeja de 288 celdas para la masa seca aérea (MSa) y de raíz (MSr), es posible que este factor haya influenciado el desarrollo de las raicillas, factor que puede considerarse en otros estudios. MARQues et al. (2003) trabajando con lechuga, encontraron menor longitud de raíz y acúmulo de masa fresca y seca en las bandejas de 288 células cuando comparado a volúmenes de 128 y 200 células. Con relación a la calidad, las mudas producidas en bandejas de $121,2 \mathrm{~cm}^{3}$ y $36,2 \mathrm{~cm}^{3}$ presentaron mayor vigor, hojas verdes y plantas uniformes en el crecimiento (sin alargamiento), sanas, con suficiente acúmulo de raíces a partir de la segunda fecha de trasplante. En la primera fecha de trasplante, el acúmulo de raíces todavía se presentaba insuficiente para todas las edades, presentando desterronamiento al momento del trasplante. Las mudas producidas en bandejas de $14,0 \mathrm{~cm}^{3}$ presentaron crecimiento poco vigoroso, menor acúmulo de raíces y llegaron a presentar hojas con clorosis en las dos últimas fechas de trasplante. Las mudas provenientes de las bandejas de $12,0 \mathrm{~cm}^{3}$ presentaron alargamiento, crecimiento desuniforme y raquítico, debido tal vez, a la alta densidad de mudas en la bandeja, que fue acentuándose a partir de la tercera semana de desarrollo de la muda.

\section{Producción en el campo}

La influencia del volumen de la celda fue observada, principalmente, en la precocidad de las plantas provenientes de mudas desarrolladas en los volúmenes mayores (121,2 y $34,6 \mathrm{~cm}^{3}$ ) donde se obtuvo mayor número (NPf) y masa precoz de frutos por planta (MPf) (Tabla 1), obteniéndose interacción entre el volumen y la edad de la muda para esa característica. SeAbra et al. (2004) encontraron ese mismo resultado en mudas de pepino, y agregan que, probablemente la precocidad sea un reflejo de la calidad de las mudas, debido a que éstas presentan mayor equilibrio entre la parte aérea y el sistema radicular y no presentaron estrés pos-trasplante. Para el número (NCf) y masa comercial de frutos planta ${ }^{-1}$ (MCf) y la masa total de frutos (MTf) planta ${ }^{-1}$, no se encontró influencia del volumen. Por otro lado el número total de frutos (NTf) fue influenciado por la edad de trasplante de la muda, presentando diferencia estadística, la edad de trasplante de 24 días en relación a la edad de 34 días, no presentando diferencia estadística para las otras edades evaluadas (Tabla 1). Para esas características, la interacción entre la edad de la muda y el volumen de celda no fue significativa, sin embargo para los factores considerados separadamente, edad y volumen, se obtuvo significancia estadística. Así tenemos que las plantas provenientes de mudas de 24 DDS fueron las más productivas en términos de precocidad $\left(1484,5\right.$ g planta $\left.^{-1}\right)$. Las mudas de 19 y 29 DDS tuvieron una producción precoz entre $400 \mathrm{a} 600 \mathrm{~g}_{\text {planta }}{ }^{-1}$ menos en relación a las mudas de 24 DDS. La muda trasplantada a los 34 DDS tuvo una diferencia de precocidad menor, de hasta 1000 g planta $^{-1}$ en relación a la muda trasplantada a los 24 días de edad (Tabla 1), observándose que mudas muy jóvenes o muy viejas no son apropiadas para la obtención de frutos precoces en el campo ya que afectan el número total y la masa de frutos.

Tabla 1. Número (NPf) frutos precoces, número total (NTf) y comercial (NCf), masa precoz de frutos (MPf), masa total (MTf) y comercial (MCf) de frutos de tomate 'Neptuno' por planta en función del volumen de la celda y la edad de trasplante de las mudas (días después de la siembra)

\begin{tabular}{|c|c|c|c|c|c|c|}
\hline $\begin{array}{l}\text { Volumen } \\
\left(\mathrm{cm}^{3}\right)\end{array}$ & $\begin{array}{l}\text { NPf } \\
\text { (unid.) }\end{array}$ & $\begin{array}{l}\text { NCf } \\
\text { (unid.) }\end{array}$ & $\begin{array}{l}\text { NTf } \\
\text { (unid.) }\end{array}$ & $\begin{array}{r}\text { MPf } \\
(\mathrm{g})\end{array}$ & $\begin{array}{r}\text { MCf } \\
(\mathrm{g})\end{array}$ & $\begin{array}{r}\text { MTf } \\
(\mathrm{g})\end{array}$ \\
\hline 121,2 & $9,40 \mathrm{a}$ & $69,2 \mathrm{a}$ & 71,2 a & 1180,2 a & 7820,0 a & 7942,2 a \\
\hline 34,6 & $9,34 \mathrm{a}$ & $68,0 \mathrm{a}$ & $69,7 \mathrm{a}$ & $1212,9 \mathrm{a}$ & $7799,3 \mathrm{a}$ & $7973,0 \mathrm{a}$ \\
\hline 12,0 & $6,13 b$ & $59,0 \mathrm{a}$ & $60,6 \mathrm{a}$ & 724,8 b & 6766,5 a & $6885,7 \mathrm{a}$ \\
\hline 14,0 & $5,91 \mathrm{~b}$ & $57,4 a$ & $58,3 \mathrm{a}$ & 745,1 b & 7186,0 a & $7315,0 \mathrm{a}$ \\
\hline \multicolumn{7}{|c|}{$\begin{array}{l}\text { Edad de las mudas } \\
\text { (días) }\end{array}$} \\
\hline 19 & $8,1 \mathrm{~b}$ & $66,2 a b$ & $68,1 \mathrm{ab}$ & 1047,6 b & 7550,0 a & $7673,4 \mathrm{a}$ \\
\hline 24 & $12,3 \mathrm{a}$ & $69,0 \mathrm{a}$ & $71,4 \mathrm{a}$ & $1484,4 \mathrm{a}$ & $7884,0 \mathrm{a}$ & $8076,0 \mathrm{a}$ \\
\hline 29 & $7,3 \mathrm{~b}$ & $63,5 a b$ & $65,4 a b$ & 845,1 bc & $7376,0 \mathrm{a}$ & $7528,0 \mathrm{a}$ \\
\hline 34 & $3,1 \mathrm{~b}$ & $54,8 \mathrm{~b}$ & $55,6 \mathrm{~b}$ & $511,7 \mathrm{c}$ & $6761,0 \mathrm{a}$ & 6839,2 a \\
\hline C.V. & 16,73 & 17,9 & 18,1 & 34,2 & 16,7 & 17,2 \\
\hline DMS & 0,49 & 12,6 & 13,1 & 369,2 & 1379,9 & 1437,6 \\
\hline
\end{tabular}

Medias seguidas por la misma letra, en las columnas, no difieren estadísticamente por el test de Tukey p>0,05. 
En relación a la influencia de la edad de trasplante, la edad de 24 DDS, presentó diferencia estadística para número de frutos totales en relación a la edad de 34 DDS, sin presentar diferencia de las otras edades de trasplante (Tabla 1). Para la masa comercial y total planta $^{-1}$, no hubo diferencias entre todas las combinaciones utilizadas, no encontrándose interacción entre el volumen y la edad de trasplante.

En relación al número de frutos, mudas de 24 días tuvieron producción superior de frutos comerciales (69, 0 frutos planta $\left.{ }^{-1}\right)$, pero estadísticamente fue igual a las mudas de 19 y 29 días cuyos números de frutos estuvieron entre 66,2 y 63,5 frutos por planta respectivamente. Las mudas de 34 días tuvieron producción inferior para número comercial $(54,8)$ y total de frutos $(55,6)$ cuando comparadas a las mudas de 24 días, pero estadísticamente igual a las mudas de 19 y 29 días. De acuerdo a las condiciones de este experimento la mejor edad para el trasplante es a los 24 DDS, aunque puede ser realizada también a los 19 y 29 DDS para el tomate tipo italiano obteniéndose incremento de frutos precoces, comerciales y totales, aunque sin diferencias para la masa comercial y total, inclusive para la edad de 34 DDS (Tabla 1). La edad de 19 días, para todos los volúmenes estudiados, puede considerarse muy precoz, ya que la muda se presenta aun con el sistema radicular poco desarrollado y también puede presentar desterronamiento al momento del trasplante, lo que podría comprometer su desarrollo pos trasplante en el campo, como ocurrió en este experimento, en que hubo lluvias fuertes en la semana de trasplante y el número de plantas del ensayo fue afectado, ya que de ocho plantas centrales que iban a evaluarse se disminuyó a seis plantas. Por otro lado, es probable que si fueran producidas en cultivo protegido no presenten los inconvenientes propios de mudas trasplantadas muy jóvenes en el campo. Si las condiciones de campo son favorables, las mudas más jóvenes tienen una satisfactoria producción de raíces y una gran capacidad de crecimiento vegetativo en relación a las plantas más viejas (Weston y Zandstra, 1989). En condiciones menos favorables de campo (vientos y lluvias fuertes) las mudas muy jóvenes tienen pocas oportunidades de sobrevivencia. De acuerdo a Alvarenga (2004) en el trasplante de mudas de tomate, las raíces secundarias se desenvuelven rápidamente, tornándose mas ramificadas y superficiales. Esa situación puede favorecer la rápida recuperación de la planta y la formación de la parte aérea sin afectar el trasplante en diferentes edades, ligada a los factores adecuados que favorecen el desarrollo del cultivar como luz, agua, nutrientes entre otros. El problema aparece cuando las condiciones son extremas, donde solamente las mudas protegidas y saludables podrán desenvolverse y producir en forma óptima. Es probable que esa edad de trasplante, haya sido afectada por temperaturas calurosas de la época disminuyendo el cuajado de frutos, ocasionando el aborto de flores. El volumen de celda de $14,0 \mathrm{~cm}^{3}$, correspondiente a la bandeja de 450 celdas, es utilizado para producción de mudas de tomate tipo industrial en algunas regiones del Brasil, como Goiania, el cual posee un manejo de producción diferente al tomate de mesa. En este trabajo puede decirse, que para la producción de tomate tipo italiano a campo, a pesar de no afectar la producción total, esta bandeja no es la más adecuada, a pesar de reunir las condiciones de uniformidad y crecimiento, entre los 15 y 24 días. Eventualmente pueden ser afectadas por condiciones climáticas adversas y las mudas deben ser preparadas con mucho cuidado de manera que la calidad de las mismas no sea afectada. Sin embargo, es probable que con un manejo adecuado de fertilización y de otros factores como luz sea posible la obtención de mudas de mejor calidad, ya que la producción de frutos en el campo no fue afectada. La calidad de los frutos obtenidos también fue muy satisfactoria de acuerdo a los parámetros propios de la variedad, color, forma y tamańo del fruto, los cuales, no fueron afectados por los tratamientos.

\section{CONCLUSIONES}

La utilización de la bandeja de 450 celdas, para producción de mudas de tomate de mesa tipo italiano en condiciones de campo, es factible, pero considerando la realización del trasplante en edades precoces de muda. La bandeja de 128 celdas es la más favorable para la producción de mudas de tomate tipo italiano y la mejor edad para el trasplante es de 24 días después de la siembra, pudiendo ser realizadas también en las edades de 19 y 29 días después de la siembra.

La edad de trasplante afecta el número de frutos precoces, comerciales y totales y la masa de frutos precoces, sin embargo, la edad y el volumen de celda no afectan la producción comercial y total del tomate tipo italiano.

\section{AGRADECIMIENTOS}

A la CAPES por concesión de la beca de estudios que posibilitó la realización del proyecto. Al Prof. Dr. Paulo Cesar Tavares de Melo por la donación de semillas para la realización de este trabajo, provistas por la empresa EAGLE.

\section{REFERENCIAS}

ALVARENGA, M.A.R. Tomate: produção em campo, em casa-devegetação e em hidroponia. Lavras: UFLA, 2004. 400p.

BRASIL. Lei $\mathrm{n}^{\circ}$ 6305, de 15 de dezembro de 1975. Dispóe sobre normas de identidade, qualidade, acondicionamento e embalagem de tomate para fins de comercializaçáo. Diário Oficial, Brasília, 30 ago.1995. Disponível em: <http: www.pr.gov/claspar/pdftomate. pdf.> Acesso em: 15/10/ 2007. 
GODOY, M.C.; CARDOSO, A.I.I. Produtividade da couve-flor em função da idade de transplantio das mudas e tamanho de celulas na bandeja. Horticultura Brasileira, v.23, p.837-840, 2005.

LATIMER, J.G. Container size and shape influence growth and landscape performance of marigold seedling. HortScience, v.26, p.124-126, 1991.

LIU, A.; LATIMER, J.G. Root cell volume in the planter flat affects watermelon seedling development and fruit yield. HortScience, v.30, p.242-246, 1995.

MARQUES, P.A.A.; BALDOTTO, P.V.; SANTOS, A.C.P.; OLIVEIRA, L. Qualidade de mudas de alface formadas em bandejas de isopor com diferentes números de células. Horticultura Brasileira, v.21, p.649-651, 2003.

MINAMI, K. Produção de mudas de alta qualidade em horticultura. Piracicaba: Degaspari, 2010. 440p.

PEREIRA, P.R.G.; MARTINEZ, H.E.P. Produção de mudas para o cultivo de hortaliças em solo e hidroponia. Informe Agropecuário, v.20, p.24-31, 1999.

RIZZO, A.A.N.; QUIJANO, F.G.; LAURA, V.A.; CARDOSO, A.I.I. Efeito da idade de mudas no desenvolvimento de meláo rendilhado. Horticultura Brasileira, v.18, p.468-469, 2000. Suplemento.

RUFF, M.; KRIZEC, D.; MIRECKI, R.; INOUYE, D. Restricted root zone volume: Influence on growth and development of tomato.
Journal of the American Society for Horticultural Science, v.112, p.763-769, 1987.

SEABRA, J.S.; GADUN, J; CARDOSO, A.I.I. Produção de pepino em função da idade de mudas produzidas em recipientes com diferentes volumes de substrato. Horticultura Brasileira, v.22, p.610-613, 2004.

TRANI, P.E.; NOVO, M.C.S.S.; CAVALLARO JUNIOR, M.L.; TELLES, L.M.G. Produçáo de mudas de alface em bandejas e substratos comerciais. Horticultura Brasileira, v.22, p.290-294, 2004.

VABRINA, C.S.; ORZOLECK. Tomato transplant age: a review. HortTechnology, v.3, p. 313-316, 1993.

VABRINA, C.S. An introduction to the production of containerized vegetable transplants. Gainesville: University of Florida, 2002. (Florida Agricultural Experiment Series Folder, HS849). Disponível em: <http://edis.ifas.ufl.edu/pdf files/hs/hs12600.pdf.> Acesso em: 29/8/2007.

WESTON, L.A.; ZANDSTRA, B.H.. Transplant age and N and $P$ nutrition effects on growth and yield of tomatoes. HortScience, v.24, p.88-90, 1989.

ULLE, J.A. Comportamiento post-transplante de tomates y berenjenas, provenientes de diferente volumen de contenedor y mezclas de substratos, a base de vermicompost, turba, perlita. Buenos Aires: Instituto Nacional de Tecnologia Agropecuaria (INTA), 2009. 263p. (Informe Técnico 2009 del Centro Regional Buenos Aires Norte) 